\title{
Chiral enantioresolution of cathinone derivatives present in "legal highs", and enantioselectivity evaluation on cytotoxicity of 3,4-methylenedioxypyrovalerone (MDPV)
}

\author{
Bárbara Silva $^{1,2}$ - Carla Fernandes ${ }^{2,3}$ - Maria Elizabeth Tiritan ${ }^{2,3,4}$. \\ Madalena M.M. Pinto ${ }^{2,3} \cdot$ Maria João Valente ${ }^{1}$ Márcia Carvalho ${ }^{1,5}$. \\ Paula Guedes de Pinho $^{1} \cdot$ Fernando Remião ${ }^{1}$
}

Received: 20 April 2016/Accepted: 19 May 2016/Published online: 13 June 2016

(C) Japanese Association of Forensic Toxicology and Springer Japan 2016

\begin{abstract}
Recently, great interest has been focused on synthetic cathinones since their consumption has increased exponentially. All synthetic cathinones exist as chiral molecules; the biological and/or toxicological properties of cathinones generally differ according to the enantiomers in human body. In this study, a chiral liquid chromatography method was developed to separate and determine the enantiomeric ratio of synthetic cathinones present in "legal highs" acquired in old smart shops or over the Internet. All the synthetic cathinones were efficiently enantio-separated with $\alpha$ and Rs ranging from 1.24 to 3.62 and from 1.24 to 10.52 , respectively, using polysaccharide-based chiral stationary phases. All synthetic cathinones, with the exception
\end{abstract}

Bárbara Silva

barbara_sofia_21@hotmail.com

Carla Fernandes

cfernandes@ff.up.pt

1 UCIBIO-REQUIMTE, Laboratório de Toxicologia, Departamento de Ciências Biológicas, Faculdade de Farmácia, Universidade do Porto, Rua Jorge Viterbo Ferreira, 228, 4050-313 Porto, Portugal

2 Laboratório de Química Orgânica e Farmacêutica, Departamento de Ciências Químicas, Faculdade de Farmácia, Universidade do Porto, Rua de Jorge Viterbo Ferreira 228, 4050-313 Porto, Portugal

3 Centro Interdisciplinar de Investigação Marinha e Ambiental (CIIMAR/CIMAR), Universidade do Porto, Rua dos Bragas 289, 4050-123 Porto, Portugal

4 Instituto de Investigação e Formação Avançada em Ciências e Tecnologias da Saúde (IINFACTS), CESPU, Rua Central de Gandra, 1317, 4585-116 Gandra PRD, Portugal

5 FP-ENAS, CEBIMED, Fundação Ensino e Cultura Fernando Pessoa, Universidade Fernando Pessoa, Praça de 9 de Abril, 349, 4249-004 Porto, Portugal of 4-methylethcathinone (4-MEC), were present in the commercialized "legal highs" in an enantiomeric proportion of 50:50. One of the studied chiral compounds was 3,4-methylenedioxypyrovalerone (MDPV), one of the most consumed cathinone derivative worldwide. Our research group has recently reported its hepatotoxicity in the racemic form. Thus, the analytical enantioresolution of the MDPV was scaled up to multi-milligram using a semipreparative amylose tris-3,5-dimethylphenylcarbamate column $(20 \mathrm{~cm} \times 7.0 \mathrm{~mm}$ ID, $7 \mu \mathrm{m}$ particle size $)$. Both enantiomers were isolated with high enantiomeric purity (enantiomeric excess $>99 \%$ ). The toxicity of $S$-(-)MDPV and $R-(+)-M D P V$ was evaluated, for the first time, using primary cultures of rat hepatocytes. It was also possible to verify that MDPV enantiomers showed hepatotoxicity in a concentration-dependent manner, but displayed no enantioselective toxicity in this cell culture model.

Keywords "Legal highs" · Synthetic cathinones . Enantioresolution - MDPV enantiomer · Cytotoxicity according to enantiomers

\section{Introduction}

In the early twenty-first century, the "legal highs" market was started [1]. The speed of emergence and effectiveness of these new psychotropic drugs appearing in the market via "smart shops" or the Internet, circumventing the implemented laws in many countries around the world, have generated a huge concern in the legislation and scientific community [2]. The most common constituents of the "legal highs" are analogs of the natural cathinone, found in the plant Catha edulis (Khat), and are obtained by 
synthesis [3]. This trend has been demonstrated to be true considering that only during 2014, in a total of 101 new psychoactive substances, 31 were synthetic cathinones [4]. Currently, there are no commercial devices for the routine screening of these compounds [5]. Cathinone's chronic abuse may result in adverse effects such as anxiety, hallucinations, paranoid agitation, hypertension, delusions, hyperreflexia, and tachycardia, and may eventually lead to acute liver and/or kidney failure and rhabdomyolysis [3]. Moreover, the synthetic cathinones have been involved in an increased number of fatalities [6]. Because of this and the fact that new cathinones continue to be consumed and synthesized [7-9], the study of these compounds is of enormous interest, as they are potentially dangerous to consumers' health.

Cathinone and all derivatives are chiral and, as a consequence, their biological and toxicological activities can differ for each of the enantiomers. Actually, it is well known that in a chiral environment such as the human body, the enantiomers may have different biological activities and different intensity of action; sometimes the effect can be limited to only one enantiomer with another often responsible for side effects or even high toxicity [10]. Literature concerning information of the isolated enantiomers of synthetic cathinones is scarce. Nevertheless, the evidence of enantioselectivity was demonstrated with higher stimulating effects of the $S-(-)$ enantiomer of methcathinone when compared to the $R-(+)$ enantiomer [11-13]. Moreover, Greg et al. [14] studied the mephedrone enantioselectivity and discovered that $R$-mephedrone was much less potent than $S$-mephedrone as a substrate at 5-hydroxytryptamine transporters. Gannon et al. [15] showed recently that the S-3,4-methylenedioxypyrovalerone ( $S$-MDPV) enantiomer is likely responsible for the majority of biologic effects of racemate. Thus, the development of analytical and semi-preparative enantioresolution methods is crucial to further toxicological studies of both enantiomers.

Considering analytical application, several techniques related to the enantiomeric resolution of synthetic cathinones were described, including capillary electrophoresis [16-20], gas chromatography [21-25], liquid chromatography (LC) [25-30], and capillary electrochromatography [31]. Among all of these works, there are only three reports related to the enantiomeric separation of synthetic cathinones by LC using chiral stationary phases (CSPs): Mohr et al. [26] described the separation of the enantiomers of 19 derivatives of cathinones with the Chiralpak ${ }^{\circledR}$ AS-H column; the enantiomers of methcathinone and cathinone were separated by Perera et al. [27] using the $(S, S)$-Whelk$\mathrm{O}^{\circledR} 1$, and Wolrab et al. [30] described the enantioseparation of cathinone derivatives using chiral ion-exchange type stationary phases.
Regarding preparative resolution by LC, the enantiomers of MDPV were separated after derivatization [28]. To our knowledge, this is the first report regarding the preparative enantioresolution of cathinones by using CSPs.

Recently, in our group, 27 samples of "legal highs", obtained in the old "smart shops", were analyzed by gas chromatography-mass spectroscopy (GC-MS) and nuclear magnetic resonance (NMR) spectroscopy, and concluded that the majority of the compounds present in these samples were synthetic cathinones [32]. The in vitro hepatotoxic effects of individual synthetic cathinones were evaluated, and pentedrone and MDPV proved to be the most potent with $\mathrm{EC}_{50}$ values of 0.664 and $0.742 \mathrm{mM}$, respectively, which are similar to that of methylenedioxyamphetamine (MDMA) [32].

Taking into account all the features stated above, to go deeper and to consider the stereochemistry of the cathinones, the enantiomeric ratio quantification of the synthetic cathinones present in the "legal highs" previously identified is crucial. Herein, firstly we described the analytical separation of the enantiomers of nine synthetic cathinones (Fig. 1) present in 14 "legal highs", by LC through different types of CSPs, for determination of the enantiomeric ratios.

Secondly, considering the cytotoxic effects of MDPV [32], one of the most consumed cathinone derivatives worldwide, we evaluated the in vitro hepatotoxicity of both enantiomers of MDPV that were quantitatively separated with the semi-preparative tris-3,5-dimethylphenylcarbamate amylose CSP, under normal phase elution conditions by multiple injections. Primary cultures of rat hepatocytes were used for the in vitro cytotoxicity evaluation of each enantiomer of MDPV, because acute or fulminant hepatic failure has been described in many cases of intoxications following the consumption of cathinone derivatives $[33,34]$. As far as we know, this is the first report dealing with in vitro hepatotoxic effects of each MDPV enantiomer.

\section{Materials and methods}

\section{Samples for analyses}

Fourteen formulations of "legal highs" (Table 1) were acquired at "smart shops" (Porto, Portugal) before the adoption of Portuguese Decree 54/2013, which prohibits the existence of these stores and the marketing of these products [35]. All different samples were acquired in the form of powders, except for Bliss sample A14, which was in the form of tablets. The chemical identification and percentage of the synthetic derivatives present in "legal 
<smiles>CC[C@H](NC)C(=O)c1ccccc1</smiles>

Buphedrone<smiles>CN[C@@H](C)C(=O)c1ccc(F)cc1</smiles>

Flephedrone<smiles>CCN[C@@H](C)C(=O)c1ccc(C)cc1</smiles>

4-MEC<smiles>CN[C@@H](C)C(=O)c1ccc(C)c(C)c1</smiles>

3,4-DMMC<smiles></smiles>

Methedrone<smiles>CCC[C@H](C(=O)c1ccc2c(c1)OCO2)N1CCCC1</smiles>

MDPV<smiles>CCNC(C)C(=O)c1ccccc1</smiles>

Ethcathinone<smiles>CN[C@@H](C)C(=O)c1ccc2c(c1)OCO2</smiles>

Methylone

Fig. 1 Chemical structures of buphedrone, 3,4-dimethylmethcathinone (3,4-DMMC), ethcathinone, flephedrone, methedrone, methylone, 4-methylethcathinone (4-MEC), 3,4- methylenedioxypyrovalerone (MDPV) and pentedrone

Table 1 Fourteen "legal high" products used in this study and their chemical compositions

\begin{tabular}{|c|c|c|}
\hline Sample & Product name & Chemical composition $^{\mathrm{a}}$ \\
\hline A1 & Bloom & Methedrone $(34 \%)$, pentedrone $(29 \%)$, ethcathinone $(24 \%)$, caffeine $(13 \%)$, isopentedrone $(<1 \%)$ \\
\hline A2 & Blast & Flephedrone $(87 \%)$, caffeine $(13 \%)$ \\
\hline A3 & Rush & Buphedrone $(87 \%)$, caffeine $(13 \%)$ \\
\hline A4 & Crabby & 3,4-DMMC (>99 \%) \\
\hline A5 & Cyclop & 3,4-DMMC (>99 \%) \\
\hline A6 & Bliss & Methedrone (89\%), pentedrone (5\%), 3,4-DMMC (4\%), caffeine $(<1 \%)$, isopentedrone $(<1 \%)$ \\
\hline A7 & Bliss & Methedrone $(>99 \%)$ \\
\hline A8 & Charlie & Buphedrone $(80 \%)$, ethcathinone $(19 \%)$, caffeine $(<1 \%)$ \\
\hline A9 & Charlie & Buphedrone (52\%), ethcathinone (48\%) \\
\hline A10 & Blow & 4-MEC (86 \%), MDPV (14\%), 3-MEC $(<1 \%)$ \\
\hline A11 & Blow & 4-MEC (83 \%), MDPV (8\%), caffeine $(8 \%), 3$-MEC $(<1 \%)$ \\
\hline A12 & Kick & Pentedrone $(89 \%)$, isopentedrone $(11 \%)$ \\
\hline A13 & Kick & Buphedrone $(80 \%)$, caffeine $(20 \%)$ \\
\hline A14 & Bliss $^{\mathrm{b}}$ & Methylone $(<99 \%)$ \\
\hline
\end{tabular}

Reference standards also targeted: MDPV, 4-MEC, pentedrone, methylone

a The chemical compositions described in our previous report [32]

b Tablets

highs" had been analyzed by GC-MS and NMR spectroscopy [32].

The synthetic standard cathinones methylone, pentedrone, 4-methylethcathinone (4-MEC), and MDPV were purchased over the Internet from Sensearomatic (http:// www.sensearomatic.com), and their purity was evaluated previously by mass spectrometry, NMR, and elemental analysis [32]. Their purity was higher than $98 \%$. 


\section{Chemicals}

Ethanol (EtOH), 2-propanol (2-PrOH), $n$-hexane (Hex), for LC purpose, were purchased from Sigma-Aldrich (St. Louis, MO, USA). Triethylamine (TEA), trifluoroacetic acid (TFA), sodium chloride ( $\mathrm{NaCl})$, anhydrous sodium sulfate $\left(\mathrm{Na}_{2} \mathrm{SO}_{4}\right)$, sodium hydroxide $(\mathrm{NaOH})$, diethyl ether, chloroform, hydrochloric acid $(\mathrm{HCl})$, and dimethyl sulfoxide (DMSO) were of analytical grade being obtained also from Sigma-Aldrich.

The Williams' E medium, collagenase type IA from Clostridium histolyticum, gentamicin, dexamethasone, bovine pancreas insulin solution, trypan blue solution, sodium pyruvate, $\beta$-nicotinamide adenine dinucleotide reduced ( $\beta$-NADH), and 3- (4,5-dimethylthiazol-2-yl)-2,5diphenyltetrazolium (MTT) were purchased from SigmaAldrich; fetal bovine serum (FBS), fungizone, and a mixture of antibiotics penicillin/streptomycin $(10,000 \mathrm{U} / \mathrm{mL} /$ $10,000 \mathrm{mg} / \mathrm{mL}$ ) from GIBCO Invitrogen (Barcelona, Spain); all other chemical reagents of analytical grade from Merck (Darmstadt, Germany).

\section{Equipment}

The LC system used consisted of a JASCO model 880-PU pump (JASCO, Tokyo, Japan), equipped with a Rheodyne model 7125 injector fitted with a $20 \mu \mathrm{L}$ or $250 \mu \mathrm{L}$ loop for analytical or semi-preparative resolution, respectively (Rheodyne, Rohnert Park, CA, USA), a JASCO model 880-30 solvent mixer, a JASCO model 875-ultraviolet (UV) detector and a QR-2090 Plus chiral polarimeter detector (JASCO). A DataApex CSW17 - chromatography station (DataApex, Prague, Czech Republic) for Microsoft Windows 95 was employed. An LC system consisted of a Finnigan Surveyor (Thermo Electron Corporation, Waltham, MA, USA) equipped with an autosampler (AutoSampler Plus) and a diode array detector TSP UV6000LP (Thermo Electron Corporation) was also employed. The treatment of the chromatographic data was performed using the Xcalibur ${ }^{\circledR} 2.0$ SUR1 software (Thermo Electron Corporation).

Optical rotation values for each enantiomer of MDPV were determined on a Polartronic Universal polarimeter with a sodium lamp (SCHMIDT + HAENSCH GmBH \& Co., Berlin, Germany), at $25^{\circ} \mathrm{C}$ (concentrations expressed in $\mathrm{mg} / \mathrm{mL}$; solvent: EtOH). The volume of the measuring cell was $1 \mathrm{~mL}$ and the optical path was $10 \mathrm{~cm}$.

\section{Preparation of sample solutions}

For analytical resolution, stock solutions of all 14 "legal high" products purchased at smart shops, and the synthetic cathinones methylone, pentedrone, 4-MEC, and MDPV were prepared by dissolution in $\mathrm{EtOH}$ at a concentration of
$1 \mathrm{mg} / \mathrm{mL}$. Working solutions were further prepared by dilution of the stock solutions in the same solvent to a concentration of $0.1 \mathrm{mg} / \mathrm{mL}$ and by addition of $0.1 \%$ TEA.

The multi-milligram separation was optimized by adjusting the sample size to scale-up of the analytical method. Solutions at $10 \mathrm{mg} / \mathrm{mL}$ of MDPV in $\mathrm{EtOH}$ were also prepared for semi-preparative separation.

The enantiomeric excess (ee) determination was carried out with ethanolic solutions of each enantiomer of MDPV at a concentration of $0.1 \mathrm{mg} / \mathrm{mL}$.

\section{Chromatographic conditions}

The analytical chromatographic columns used in this study were Chiralpak ${ }^{\circledR}$ AS-H $(15 \mathrm{~cm} \times 4.6 \mathrm{~mm}$ ID, $5 \mu \mathrm{m}$ particle size) from Chiral Technologies Europe, Daicel Chemical Industries, Ltd., Osaka, Japan, $(S, S)$-Whelk-O ${ }^{\circledR} 1(25 \mathrm{~cm}$, $4.6 \mathrm{~mm}$ ID, $5 \mu \mathrm{m}$ particle size) from Regis Technologies, Inc. (Morton Grove, IL, USA), L-Phenylglycine ${ }^{\circledR}$ column $(25 \mathrm{~cm}, 4.6 \mathrm{~mm}$ ID, $5 \mu \mathrm{m}$ particle size) also from Regis Technologies, Inc., Chirobiotic ${ }^{\circledR} \mathrm{T}(15 \mathrm{~cm} \times 4.6 \mathrm{~mm}$ ID, $5 \mu \mathrm{m}$ particle size) from Astec (Whippany, NJ, USA), and the homemade polysaccharide based columns [36, 37] consisted of amylose tris-3,5-dimethylphenylcarbamate (CSP1) and amylose tris-3,5-dimethoxyphenylcarbamate (CSP2), both coated onto APS-Nucleosil (500 ̊, $7 \mu \mathrm{m}, 20 \%$, w/w; Phenomenex, Torrance, CA, USA) and packed into a stainless-steel $15 \mathrm{~cm} \times 4.6 \mathrm{~mm}$ ID size column.

The chromatographic column for semi-preparative separation was prepared as described elsewhere [37] and is constituted by the CSP1 coated with APS-Nucleosil (500 $\AA, 7 \mu \mathrm{m}, 20 \%, \mathrm{w} / \mathrm{w})$ and packed into a stainless-steel $20 \mathrm{~cm} \times 7.0 \mathrm{~mm}$ ID size column.

All chromatographic analyses were performed at room temperature under isocratic conditions. The chromatograms were monitored by UV detection at a wavelength of $254 \mathrm{~nm}$ and polarimetric detection. The measurements were performed under normal phase elution conditions. The mobile phase compositions were Hex and EtOH or 2-PrOH with TEA as a modifier or with a mixture of TEA and TFA as additives. The mobile phases were prepared in a volume/volume relation and degassed in an ultrasonic bath for $15 \mathrm{~min}$ before use.

For analytical chromatography the flow rate used was $0.5,0.8$ or $1 \mathrm{~mL} / \mathrm{min}$. The sample injections $(20 \mu \mathrm{L})$ were carried out in duplicate. The dead time $\left(t_{0}\right)$ was considered to be equal to the peak of the solvent front and was taken from each run. The retention factor $(k)$ was calculated by the equation $k=\left(\left[t_{\mathrm{r}}-t_{0}\right] / t_{0}\right)$. The separation factor $(\alpha)$ was calculated as $\alpha=\left(k_{2} / k_{1}\right)$. The resolution factor (Rs) was calculated using the equation $\mathrm{Rs}=$ $\left(1.18\left[\operatorname{tr}_{2}-\operatorname{tr}_{1}\right] /\left[W_{10.5}+W_{20.5}\right]\right)$, where $\operatorname{tr}_{1}$ and $\operatorname{tr}_{2}$ are the retention times of the first and second enantiomers, 
respectively, and $W_{1} 0.5$ and $W_{2} 0.5$ are the corresponding peak width measured at half height. The enantiomeric ratio (ER) was determined by the relative percentages of the peak areas according to $E R=E 1 / E 2$, where [E1] and [E2] are the peak area of each enantiomer [38].

\section{Multi-milligram enantioseparation of MDPV}

Semi-preparative chromatographic separation of the enantiomers of MDPV was first achieved through multiple injections fitted with a $250 \mu \mathrm{L}$ loop, using the mobile phase Hex/EtOH/TEA (97:3:0.1, v/v), under several flow rates and $\lambda=254 \mathrm{~nm}$. The collected fractions of each enantiomer were injected $(20 \mu \mathrm{L})$, in triplicate, on the analytical column under the optimized chromatographic conditions to determine their ee. The ee was determined by the relative percentages of the peak areas according to ee $(\%)=100 \times$ $([\mathrm{E} 1]-[\mathrm{E} 2] /([\mathrm{E} 1]+[\mathrm{E} 2])$ or $100 \times([\mathrm{E} 2]-[\mathrm{E} 1] /([\mathrm{E} 2]+$ $[\mathrm{E} 1])$, where $[\mathrm{E} 1]$ and $[\mathrm{E} 2]$ are the peak area of each enantiomer [38].

All fractions of each enantiomer, obtained after multiple injections of the working solutions totaling $100 \mathrm{mg}$ amount of MDPV racemate, were combined. The chromatographic fractions combined for each enantiomer were evaporated under reduced pressure and the solid obtained was dissolved in $100 \mathrm{~mL}$ of chloroform. The organic solution was washed with $1 \mathrm{M} \mathrm{NaOH}$ solution $(5 \times 25 \mathrm{~mL})$ and saturated $\mathrm{NaCl}$ solution $(3 \times 20 \mathrm{~mL})$. The organic layer was dried with anhydrous $\mathrm{Na}_{2} \mathrm{SO}_{4}$, filtered and evaporated under reduced pressure. After elimination of TEA, both enantiomers were precipitated in organic phase by acidification. Briefly, to each enantiomer a small amount of diethyl ether was added, and then concentrated $\mathrm{HCl}$ solution was added dropwise to form the precipitate, which was collected by filtration after centrifugation $(3000 \mathrm{rpm}$, $30 \mathrm{~min}$ ). At the end of the procedure, $45.5 \mathrm{mg}$ of the first eluted MDPV enantiomer and $41.3 \mathrm{mg}$ of its antipode could be obtained.

\section{Cytotoxicity studies}

\section{Animals}

Adult male Wistar rats (Charles-River Laboratories, Barcelona, Spain) weighing 200-250 g were used to obtain primary hepatocytes. The animals were conditioned in polyethylene cages in an environment with a temperature of $20 \pm 2{ }^{\circ} \mathrm{C}$, humidity of $40-60 \%$ and a light/dark cycle at $12 \mathrm{~h} / 12 \mathrm{~h}$. The animals were provided with free access to standard chow and water ad libitum. Surgical procedures for isolation of the livers were performed under isoflurane anesthesia at 10:00-11:00 a.m.

\section{Isolation and culture of primary rat hepatocytes}

Hepatocyte isolations were performed by the collagenase perfusion method as described previously [39]. Briefly, the liver was digested by a two-step perfusion with calciumfree Hanks' salt solution followed by a solution containing collagenase. The resulting hepatocyte suspension was purified by low speed centrifugation and several washing procedures. The trypan blue exclusion test determined an initial viability of isolated hepatocytes above $85 \%$.

A suspension of 500,000 viable cells $/ \mathrm{mL}$ in complete culture medium (Williams' E medium supplemented with $10 \% \mathrm{FBS}, 0.1 \mathrm{mg} / \mathrm{mL}$ streptomycin, $100 \mathrm{U} / \mathrm{mL}$ penicillin, $2 \mathrm{ng} / \mathrm{mL}$ insulin, $10 \mathrm{ng} / \mathrm{mL}$ gentamicin, and $5 \mathrm{nM}$ dexamethasone) was seeded in 96 wells plates (BD Biosciences, Oxford, UK). The cells were incubated overnight for cell adhesion, at $37{ }^{\circ} \mathrm{C}$ with $95 \% \mathrm{O}_{2} / 5 \% \mathrm{CO}_{2}$. The next day, the cells were exposed to MDPV (racemate and each enantiomer), in a range of $0.2-1.6 \mathrm{mM}$ in serum-free culture medium, for 24 and $48 \mathrm{~h}$.

\section{MTT reduction assay}

The MTT reduction assay was performed as described previously [40]. Briefly, cells were incubated at $37{ }^{\circ} \mathrm{C}$ for $1.5 \mathrm{~h}$ with a solution of $500 \mathrm{~g} / \mathrm{mL}$ MTT. The formazan crystals, which were formed by mitochondrial succinate dehydrogenase, were dissolved in $100 \%$ DMSO, and detected at $550 \mathrm{~nm}$ in a 96-well plate reader (PowerWaveX; Bio-Tek, Winooski, VT, USA). The data were normalized with the positive and negative controls. For the positive control, untreated cells were used, while $1 \%$ Triton X-100 was used as negative control. Data were expressed as mean \pm standard deviation (SD) obtained from three independent experiments performed in quadruplicate for each concentration.

\section{Lactate dehydrogenase release assay}

The lactate dehydrogenase (LDH) activity was determined by the decrease in $\beta-\mathrm{NADH}$ absorbance during the reduction of pyruvate to lactate as described previously [41] with some modifications. After exposure of the cells to each enantiomer, the plates were centrifuged at $250 \mathrm{~g}$ for $10 \mathrm{~min}$. A $50-\mu \mathrm{L}$ volume each of the incubation medium from each well was transferred into new plates (dilutions prepared in phosphate buffer: $50 \mathrm{mM} \mathrm{KH}_{2} \mathrm{PO}_{4}, \mathrm{pH}$ 7.4) and $200 \mu \mathrm{L}$ of $0.21 \mathrm{mM} \beta-\mathrm{NADH}$ (prepared in phosphate buffer) was added. After addition of $25 \mu \mathrm{L}$ of $22.7 \mathrm{mM}$ sodium pyruvate, the oxidation of $\beta-\mathrm{NADH}$ to $\beta-\mathrm{NAD}^{+}$ was monitored at $340 \mathrm{~nm}$ in a 96 well plate reader. The data were normalized with positive and negative controls. 
For the positive control, $1 \%$ Triton $\mathrm{X}-100$ was used. Untreated cells were used as negative control. Data were reported as mean $\pm \mathrm{SD}$ of three independent experiments performed in quadruplicate.

\section{Results and discussion}

\section{Enantiomeric resolution of cathinone derivatives present in "legal high" products}

Recently, LC using CSPs has emerged as one of the most helpful and highly applicable methods for enantioresolution [42], determination of enantiomeric purity [43, 44] and preparation of enantiomerically pure compounds [37]. Thus, a growing number of CSPs have become available and are now routinely used [45]. Nowadays, polysaccharide-based, macrocyclic antibiotics-based and Pirkle-type CSPs are pointed out as the most successful for analytical and preparative separations of enantiomers [46]. In this work, these three different types of CSPs were chosen to investigate the enantioresolution of nine cathinone derivatives (Fig. 1) present in 14 "legal high" products to determine further their enantiomeric ratios. The chemical compositions of the "legal high" products were investigated and are listed in Table 1 [32].

Initially, only the samples with one synthetic cathinone in its composition, being present in a percentage higher than $20 \%$ (Blast A2, Rush A3, Crabby A4, Cyclop A5, Bliss A6, Bliss A7, Blow A10, Blow A11, Kick A12, Kick A13, and Bliss A14), and standards (methylone, pentedrone, 4-MEC, and MDPV) were analyzed. Based on the literature, the commercial CSPs $(S, S)$-Whelk-O ${ }^{\circledR} 1$ [27] and Chiralpak ${ }^{\circledR}$ AS-H [26] were chosen to start this study.

Regarding $(S, S)$-Whelk-O ${ }^{\circledR} 1$, a mobile phase consisting of Hex/2-PrOH/TEA/TFA (90:10:0.05:0.05, v/v/v/v) was firstly used; however, no enantiomeric separation was obtained. To overcome this situation, EtOH was evaluated as organic modifier being an alternative to 2-PrOH. Thus, with the mobile phase Hex/EtOH/TEA/TFA (90:10:0.05:0.05, $\mathrm{v} / \mathrm{v} / \mathrm{v} / \mathrm{v}$ ), a slight separation of the enantiomers of methedrone present in sample Bliss A7 was observed. An increase in the amount of Hex improved the enantioselectivity $(\alpha=1.12)$ and resolution (Rs $=1.79)$ (Fig. 2).

Considering that methedrone was the only synthetic cathinone resolved on $(S, S)$-Whelk-O ${ }^{\circledR} 1$, the Chiralpak ${ }^{\circledR}$ AS-H CSP was attempted to resolve the enantiomers of the samples with one synthetic cathinone in its composition (Table 1). Mobile phase Hex/2-PrOH/TEA (97:3:0.1, v/v/ v) with different flow rates were used namely $0.5,0.8$, and $1 \mathrm{~mL} / \mathrm{min}$ to achieve this aim. Eight of nine synthetic cathinones were enantioseparated with excellent enantioselectivity on Chiralpak ${ }^{\circledR}$ AS-H CSP, with $\alpha$ and Rs ranging from 1.24 to 3.62 and from 1.24 to 10.52 , respectively (Table 2). MDPV was the only synthetic cathinone not resolved on Chiralpak ${ }^{\circledR}$ AS-H CSP. A set of chromatograms, at optimized elution conditions, for synthetic cathinones, is depicted in Fig. 3. Once the enantiomeric resolution became possible for the cathinones present in the samples with only one cathinone (except MDPV), all the remaining samples (Table 1) were injected under the same chromatographic conditions.

It was possible to separate and identify both enantiomers of most of cathinone derivatives present in all the "legal highs" with the Chiralpak ${ }^{\circledR}$ AS-H CSP by comparing the enantiomeric retention factors of the corresponding cathinone derivatives. Figure 4 shows an example of a representative chromatogram obtained from the sample Bloom A1, which has in its composition the cathinone derivatives methedrone, pentedrone, and ethcathinone. Although the enantiomeric separation of the synthetic cathinones present in samples with two or more cathinones was possible, in some of them the enantiomers of different cathinones had similar retention times appearing with overlapping bands. For these cathinones it was not possible to evaluate their ERs in the "legal high".

Taking into account that MDPV was separated neither by $(S, S)$-Whelk-O ${ }^{\circledR} 1$ nor by Chiralpak ${ }^{\circledR}$ AS-H CSP, its enantioseparation was attempted in four other CSPs, namely the Pirkle-type L-Phenylglycine ${ }^{\circledR}$, the antibiotic based Chirobiotic $\mathrm{T}^{\circledR}$, and two homemade polysaccharide based CSPs consisting of amylose tris-3,5dimethylphenylcarbamate (CSP1) and amylose tris-3,5dimethoxyphenylcarbamate (CSP2), both coated onto APSNucleosil. Several mobile phases and flow rates were tried (data not shown); however, enantioresolution was only achieved with polysaccharide based CSPs. The best chromatographic results were achieved with CSP1 using the mobile phase consisting of Hex/EtOH/TEA (97:3:0.1, v/v/ v) and a flow rate of $0.5 \mathrm{~mL} / \mathrm{min}$, being the elution time lower than $20 \mathrm{~min}$ (Fig. 5). The enantiomers of MDPV were resolved successfully with excellent enantioselectivity and resolution, with $\alpha$ value of 1.70 and Rs of 3.11.

The good results on the enantioselectivity and resolutions allowed the evaluation of the ERs of the synthetic cathinones present in the samples of "legal highs". The results are shown in Table 3. All synthetic cathinones were present mostly in an enantiomeric proportion of 50:50 (ER approximately 1.0) with the exception of 4-MEC standard as well as in the "legal highs" Blow A10 and Blow A11, with the (+)-enantiomer in higher amounts.

Additionally, the elution order was determinated for the synthetic cathinones 4-MEC, pentedrone, and buphedrone under the chromatographic conditions present in Table 2 using a polarimeter detector coupled to LC. The (+)-enantiomer was the first to elute in all cases. Considering the low 
Fig. 2 Liquid chromatogram of methedrone present in Bliss A7. Conditions: column: $(S, S)$ Whelk-O ${ }^{\circledR} 1$, mobile phase $n$ hexane (Hex)/ethanol (EtOH)/ triethylamine (TEA)/ trifluoroacetic acid (95:5:0.05:0.05, v/v/v/v), flow rate $1 \mathrm{~mL} / \mathrm{min}$, ultraviolet (UV) detection $254 \mathrm{~nm}$

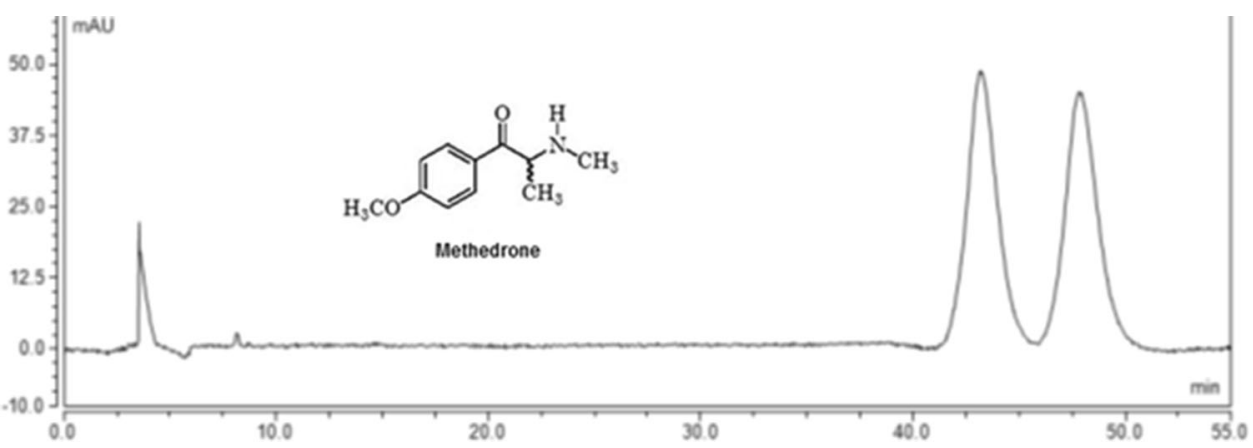

Table 2 Chromatographic data for the synthetic cathinones present in the different samples using the Chiralpak ${ }^{\circledR}$ AS-H chiral stationary phase

\begin{tabular}{|c|c|c|c|c|c|}
\hline Cathinone & Sample & $k_{1}$ & $k_{2}$ & $\alpha$ & Rs \\
\hline Flephedrone & Blast A2 & 1.93 & 3.72 & 1.93 & 6.33 \\
\hline \multirow[t]{3}{*}{ Pentedrone } & Standard & 0.82 & 1.42 & 1.79 & 8.63 \\
\hline & Kick A12 & 0.79 & 1.47 & 1.87 & 9.30 \\
\hline & Bloom A1 & 0.75 & 1.45 & 1.95 & 10.52 \\
\hline \multirow[t]{3}{*}{ 4-MEC } & Standard & 1.16 & 1.47 & 1.27 & 2.54 \\
\hline & Blow A11 & 1.09 & 1.47 & 1.35 & 3.24 \\
\hline & Blow A10 & 1.08 & 1.48 & 1.37 & 3.38 \\
\hline \multirow[t]{2}{*}{ 3,4-DMMC } & Cyclop A5 & 1.89 & 6.77 & 3.59 & 10.34 \\
\hline & Crabby A4 & 1.86 & 6.75 & 3.62 & 9.46 \\
\hline \multirow[t]{3}{*}{ Methedrone } & Bliss A7 & 6.08 & 10.39 & 1.71 & 6.79 \\
\hline & Bliss A6 & 6.01 & 10.32 & 1.72 & 6.79 \\
\hline & Bloom A1 & 5.70 & 9.79 & 1.72 & 5.39 \\
\hline \multirow[t]{4}{*}{ Buphedrone } & Kick A13 & 0.94 & 2.23 & 2.36 & 7.54 \\
\hline & Charlie A9 & 1.02 & 2.25 & 2.21 & 4.10 \\
\hline & Charlie A8 & 1.01 & 2.24 & 2.21 & 6.14 \\
\hline & Rush A3 & 0.97 & 2.27 & 2.34 & 7.62 \\
\hline \multirow[t]{2}{*}{ Methylone } & Standard & 7.58 & 13.45 & 1.77 & 7.39 \\
\hline & Bliss A14 & 7.56 & 13.53 & 1.79 & 7.47 \\
\hline \multirow[t]{3}{*}{ Ethcathinone } & Bloom A1 & 0.95 & 1.24 & 1.30 & 2.61 \\
\hline & Charlie A9 & 1.02 & 1.27 & 1.25 & 1.25 \\
\hline & Charlie A8 & 1.01 & 1.26 & 1.24 & 1.24 \\
\hline
\end{tabular}

Mobile phase conditions: $n$-hexane (Hex)/2-propanol (2-PrOH)/triethylamine (TEA) $(97: 3: 0.1, \mathrm{v} / \mathrm{v} / \mathrm{v})$, flow rate $0.5 \mathrm{~mL} / \mathrm{min}$

$k$ retention factor, $\alpha$ separation factor, $R s$ resolution factor

sensitivity of the available polarimeter it was not possible to determine the elution order of the other cathinones.

\section{Multi-milligram enantioresolution of MDPV}

MDPV is one of the most consumed cathinone derivatives worldwide and its hepatotoxicity has been demonstrated [32]. In the present study, multi-milligram resolution of both enantiomers of MDPV was performed, using a semi-preparative CSP for further cytotoxicity studies. This methodology has advantages over the indirect method, because it does not require prior derivation. Based on the analytical enantioseparation results $(\alpha=1.70$ and $\mathrm{Rs}=3.11)$, the CSP1 was chosen to scale-up to the preparative mode and isolate both enantiomers of MDPV.

The separation of MDPV enantiomers was optimized by adjusting the amount of the sample from a scale-up of the analytical method. The optimized mobile phase and the detector wavelength of the analytical system were the same, as shown in Fig. 5. The column diameter was increased from 4.6 to $7 \mathrm{~mm}$, which corresponded to a scale factor of 3. According to this factor, the flow rate was increased from 0.5 to $1.5 \mathrm{~mL} / \mathrm{min}$. Considering that MDPV has a high solubility in $\mathrm{EtOH}$, working solutions of $10 \mathrm{mg} /$ $\mathrm{mL}$ of MDPV were prepared. The loading effect in semipreparative mode was tested by injecting different volumes of the working solution. The volume of $100 \mu \mathrm{L}$ was the maximum throughput. Figure 6 shows the chromatogram obtained by semi-preparative separation of MDPV.

Multiple injections of the working solutions totaling $100 \mathrm{mg}$ of MDPV resulted in $45.5 \mathrm{mg}$ of the first eluted enantiomer and $41.3 \mathrm{mg}$ of the second eluted enantiomer, after elimination of the mobile phase additive (TEA) and precipitation of each hydrochloride enantiomer of MDPV, with a recovery rate of $86.8 \%$. The MDPV was in racemate form (Table 3), meaning that $50 \mathrm{mg}$ of each enantiomer was injected. Thus, the recovery rate was $91.0 \%$ for the enantiomer that eluted first and $82.6 \%$ for the later eluting enantiomer (Table 4). The recovery rate would be higher if the procedures of TEA removal and the formation of the hydrochloride were not necessary.

\section{Determination of enantiomeric purity and specific rotation of MDPV enantiomers}

A solution of $10 \mathrm{mg} / \mathrm{mL}$ of each single enantiomer of MDPV was prepared to measure its specific rotation in a polarimeter (Table 4). It was possible to verify that the levorotatory one was the first eluted enantiomer and the dextrorotatory one was the second eluted enantiomer. 
a

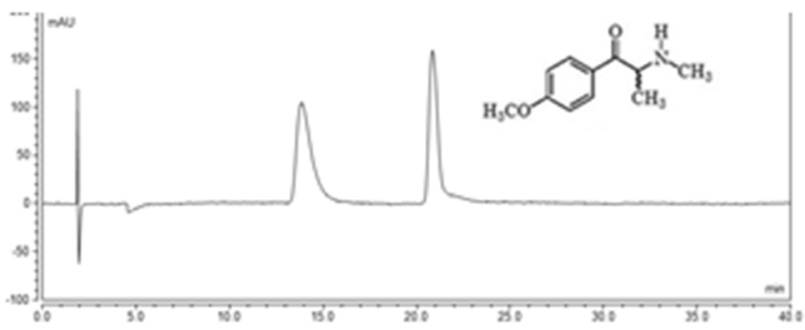

C
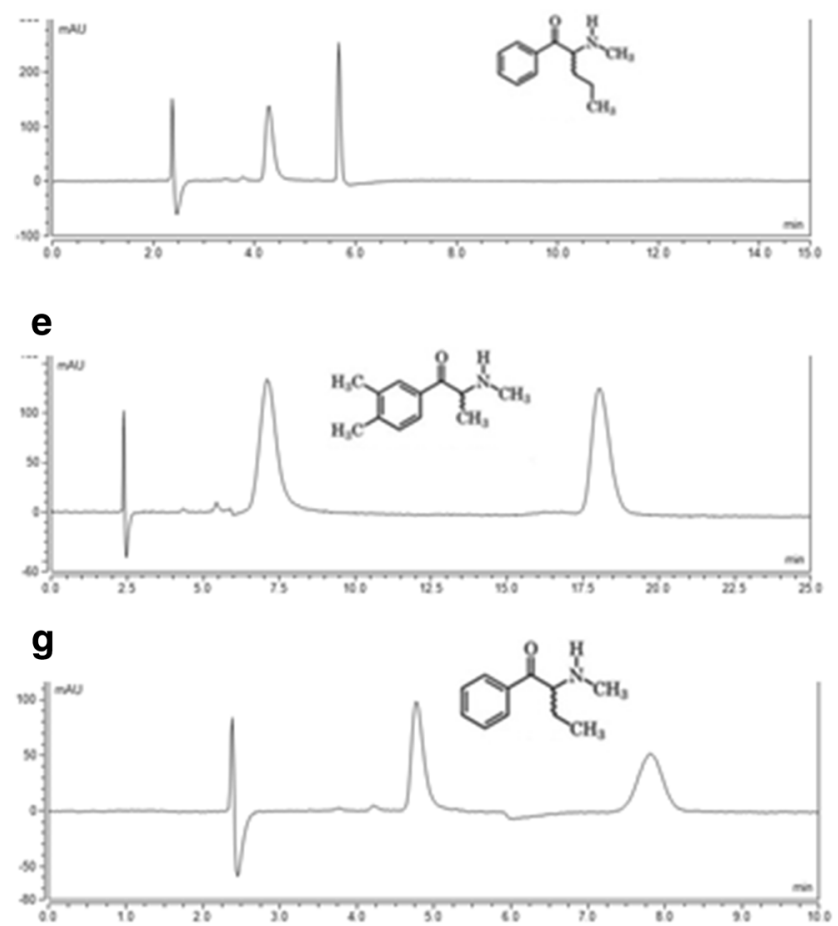

Fig. 3 Liquid chromatograms of a methedrone present in Bliss A7, b methylone, c pentedrone, $\mathbf{d}$ flephedrone present in Blast A2, e 3,4DMMC present in Cyclop A5, $\mathbf{f} 4-\mathrm{MEC}, \mathbf{g}$ and $\mathbf{h}$ buphedrone present in Kick A13. Conditions: column Chiralpak ${ }^{\circledR}$ AS-H, mobile phase b
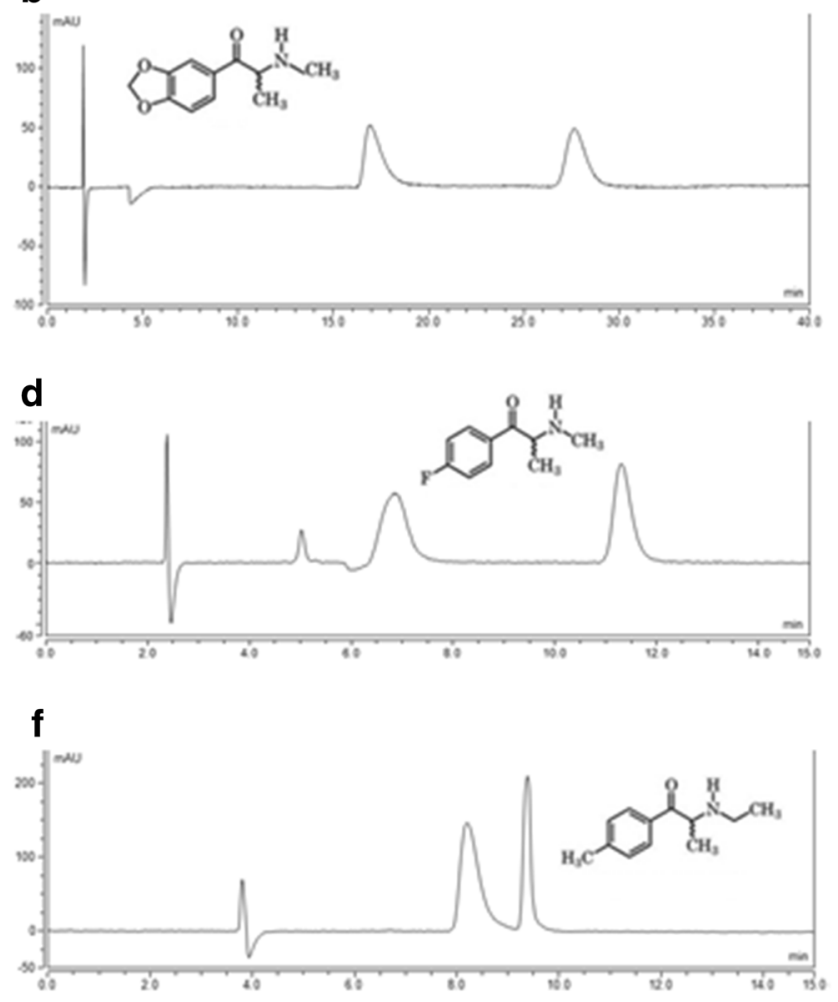

h

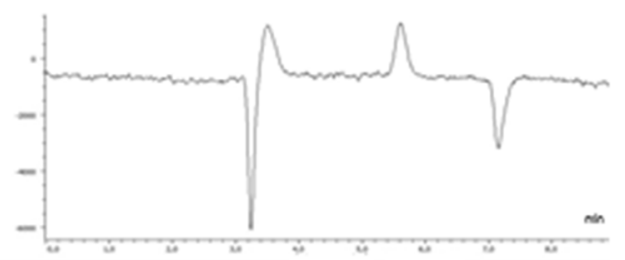

Hex/2-propanol (2-PrOH)/TEA (97:3:0.1, v/v/v), flow rate $1 \mathrm{~mL} / \mathrm{min}$ for $(\mathbf{a}, \mathbf{b}), 0.8 \mathrm{~mL} / \mathrm{min}$ for $(\mathbf{c}-\mathbf{f})$ or $0.5 \mathrm{~mL} / \mathrm{min}$ for $(\mathbf{g}, \mathbf{h}), \mathrm{UV}$ detection $254 \mathrm{~nm}(\mathbf{a}-\mathbf{g})$ or polarimeter $(\mathbf{h})$

Fig. 4 Liquid chromatogram of a pentedrone, $b$ ethcathinone, and $\mathrm{c}$ methedrone present in Bloom A1. Conditions: column Chiralpak $^{\circledR}$ AS-H, mobile phase Hex/2-PrOH/TEA (97:3:0.1, $\mathrm{v} / \mathrm{v} / \mathrm{v}$ ), flow rate $0.5 \mathrm{~mL} / \mathrm{min}$, UV detection $254 \mathrm{~nm}$

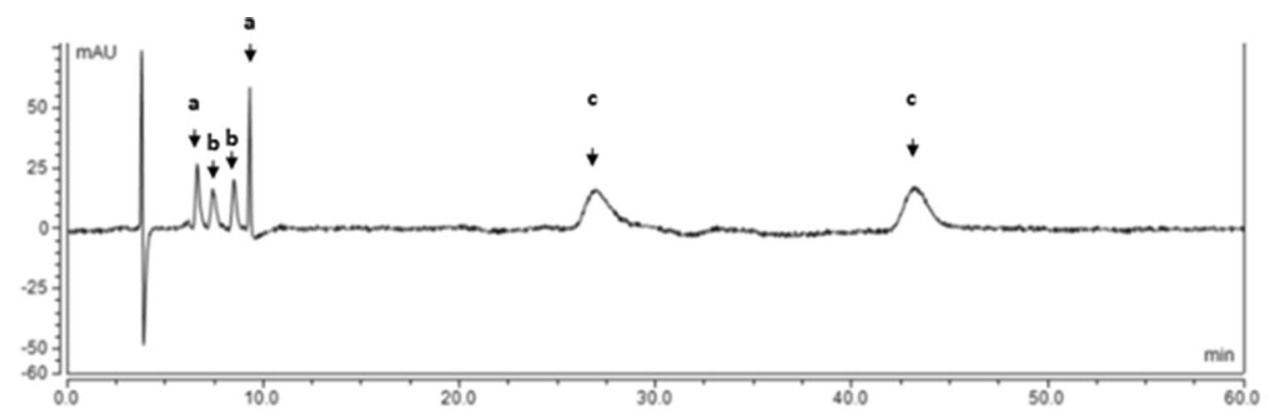

Moreover, based on a recent study that described the absolute configuration of these enantiomers by X-ray crystallography [28], it can be inferred that in this study the first enantiomer under the optimized chromatographic conditions was the $S$-(-)-MDPV and the second the enantiomer $R$-(+)-MDPV. 


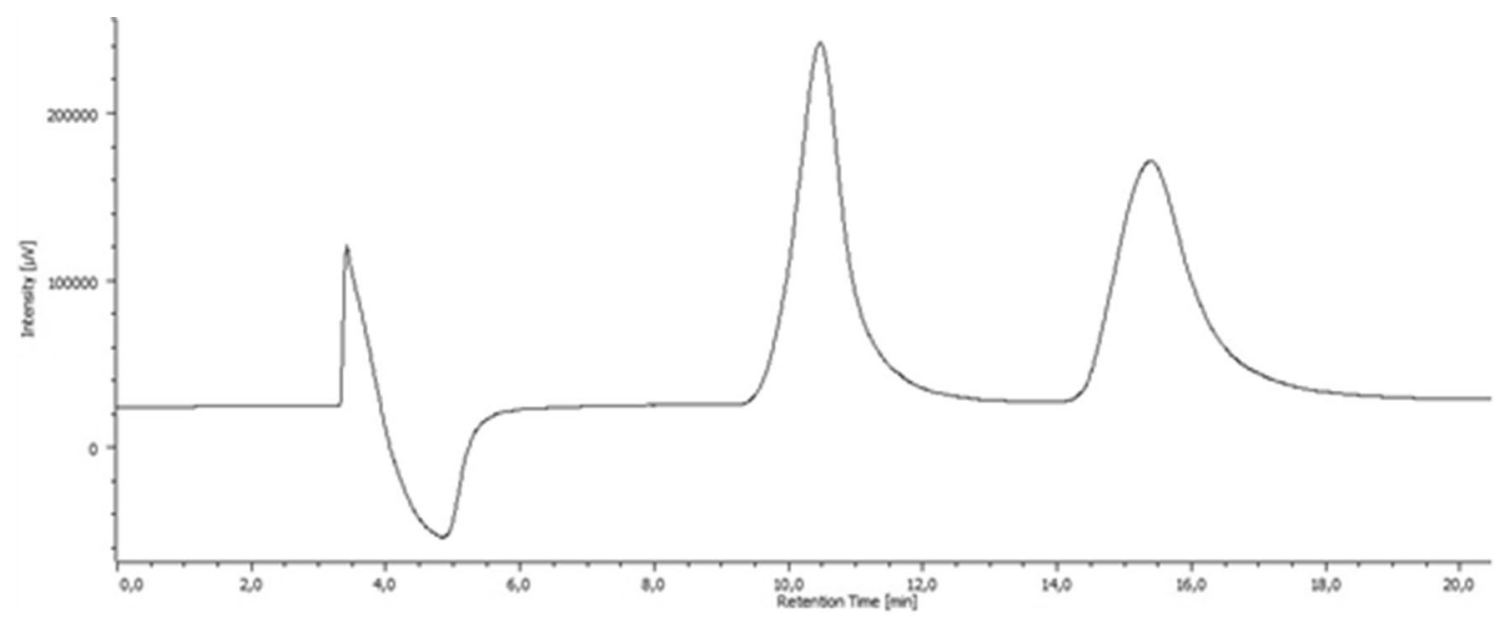

Fig. 5 Liquid chromatogram of MDPV. Conditions: column amylose tris-3,5-dimethylphenylcarbamate coated on APS-Nucleosil (CSP1), mobile phase Hex/EtOH/TEA (97:3:0.1, v/v/v), flow rate $0.5 \mathrm{~mL} / \mathrm{min}$, UV detection $254 \mathrm{~nm}$

Table 3 Enantiomeric ratios (ERs) of synthetic cathinones present in the samples of "legal highs"

\begin{tabular}{lllll}
\hline Compound & Chromatographic conditions & Area \% E1 & Area \% E2 & ER \\
\hline Blast A2 (flephedrone) & A & $50.08 \pm 0.02$ & $49.92 \pm 0.02$ & 1.00 \\
Standard pentedrone & A & $51.38 \pm 0.02$ & $48.62 \pm 0.02$ & 1.06 \\
Standard 4-MEC & A & $63.53 \pm 0.01$ & $36.47 \pm 0.01$ & 1.74 \\
Cyclop A5 (3,4-DMMC) & A & $50.02 \pm 0.02$ & $49.98 \pm 0.02$ & 1.00 \\
Bliss A7 (methedrone) & A & $47.35 \pm 0.02$ & $52.65 \pm 0.02$ & 0.90 \\
Kick A13 (buphedrone) & A & $50.27 \pm 0.01$ & $49.73 \pm 0.01$ & 1.01 \\
Standard methylone & A & $50.04 \pm 0.03$ & $49.96 \pm 0.03$ & 1.00 \\
Rush A3 (buphedrone) & A & $50.20 \pm 0.02$ & $49.80 \pm 0.02$ & 1.01 \\
Blow A11 (4-MEC) & A & $62.94 \pm 0.02$ & $37.06 \pm 0.02$ & 1.70 \\
Blow A10 (4-MEC) & A & $61.90 \pm 0.01$ & $38.10 \pm 0.01$ & 1.62 \\
Bliss A6 (methedrone) & A & $49.88 \pm 0.03$ & $50.12 \pm 0.03$ & 1.00 \\
Kick A12 (pentedrone) & A & $54.06 \pm 0.02$ & $45.94 \pm 0.02$ & 1.18 \\
Crabby A4 (3,4-DMMC) & A & $49.21 \pm 0.02$ & $50.79 \pm 0.02$ & 0.97 \\
Bloom A1 (ethcathinone) & A & $50.14 \pm 0.01$ & $49.86 \pm 0.01$ & 1.01 \\
Bloom A1 (pentedrone) & A & $50.20 \pm 0.02$ & $49.80 \pm 0.02$ & 1.01 \\
Bloom A1 (methedrone) & A & $49.76 \pm 0.02$ & $50.24 \pm 0.02$ & 0.99 \\
Bliss A14 (methylone) & A & $49.96 \pm 0.02$ & $50.04 \pm 0.02$ & 1.00 \\
Standard MDPV & B & $49.97 \pm 0.02$ & $50.03 \pm 0.02$ & 1.00 \\
\hline Condition A column: Chira & & AS-H, & &
\end{tabular}

Condition A column: Chiralpak ${ }^{\circledR}$ AS-H, mobile phase Hex/2-PrOH/TEA (97:3:0.1,v/v/v), flow rate $0.5 \mathrm{~mL} /$ min, ultraviolet (UV) detection $254 \mathrm{~nm}$

Condition B column: CSP1 coated onto APS-Nucleosil, mobile phase Hex/ethanol/TEA (97:3:0.1,v/v/v), flow $0.5 \mathrm{~mL} / \mathrm{min}$, UV detection $254 \mathrm{~nm}(n=3)$

$E 1, E 2$ peak area of each enantiomer

The determination of ee for each enantiomer was performed using the optimized chromatographic conditions associated to the best enantioselectivity. Figure 7 shows the chromatograms obtained during method development for measuring the ee values. The optimized chiral LC conditions developed allowed the accurate determination of the ee of each enantiomer of MDPV. Thus, the ee values for $S$-(-)-MDPV and $R$-(+)-MDPV were higher than 99 and $94 \%$, respectively. To optimize the enantiomeric purity of $R-(+)-\mathrm{MDPV}$, a subsequent reinjection of various fractions collected was performed, achieving an ee value higher than $99 \%$ (Fig. 7).

\section{Cytotoxicity studies}

The liver is the major target organ of xenobiotics; study of the cytotoxicity of xenobiotics in isolated hepatocytes is a main focus [47]. Primary hepatocyte cultures remain the 


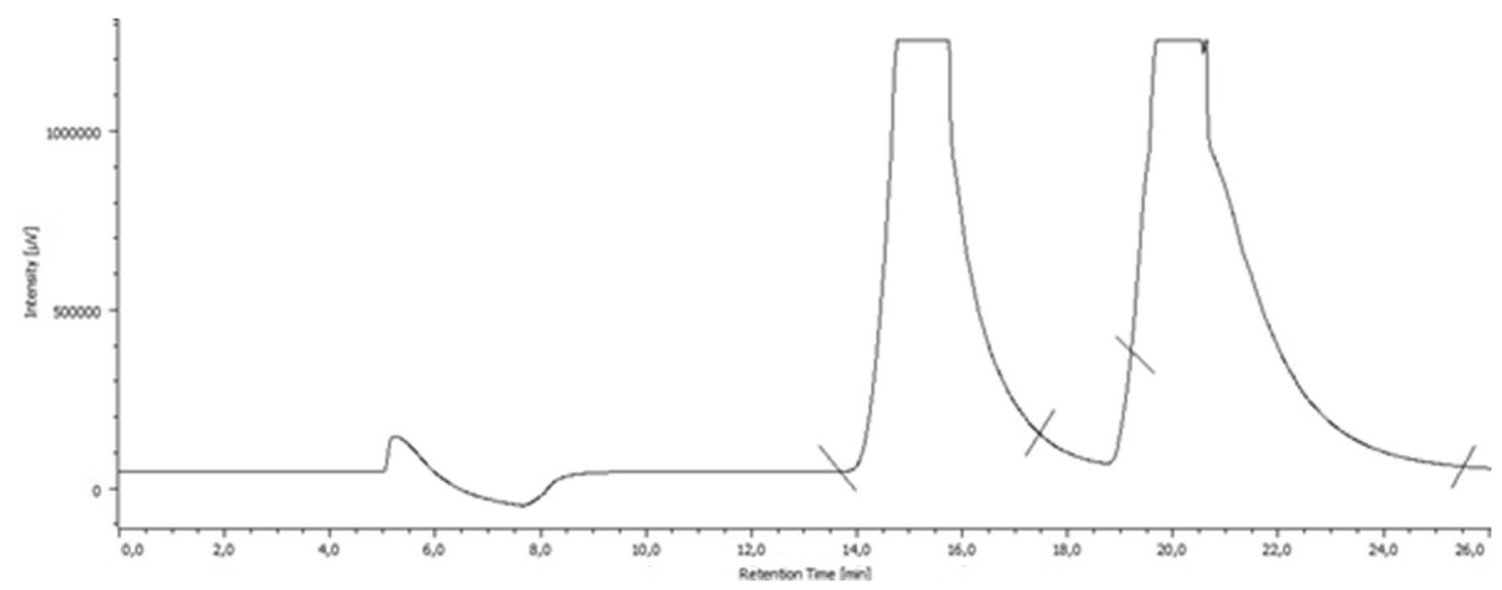

Fig. 6 Liquid chromatogram with the semi-preparative separation column for MDPV. Conditions: CSP1 semi-preparative column, mobile phase Hex/EtOH/TEA (97:3:0.1, v/v/v), flow rate $1.5 \mathrm{~mL} / \mathrm{min}$, UV detection $254 \mathrm{~nm}$

Table 4 Elution order, specific rotations, recoveries and enantiomeric excess values for the resolved enantiomers of MDPV

\begin{tabular}{lllll}
\hline Enantiomer & Elution order & {$[\alpha]_{D}^{2{ }^{\circ} \mathrm{C}}(\mathrm{c})^{\mathrm{a}}$} & Recovery $(\%)$ & $\mathrm{ee}^{\mathrm{b}}(\%)$ \\
\hline$S-(-)-\mathrm{MDPV}$ & First & $-0.23(10)$ & 91.0 & 99.1 \\
$R-(+)-\mathrm{MDPV}$ & Second & $+0.08(10)$ & 82.6 & 94.4 (99.6 after reinjection) \\
\hline
\end{tabular}

${ }^{a}$ Specific rotation in ethanol with a concentration in $\mathrm{mg} / \mathrm{mL}$

b ee enantiomeric excess determinated by chiral liquid chromatography under the conditions described in Fig. 7

standard model for metabolic studies and toxicity of xenobiotics [48]. Primary cultures of rat hepatocytes are a good alternative to human cells because they have higher metabolic responses than ordinary human cell lines and interindividual variability can be minimized by selection of animals of the same gender and age and with similar diets [49].

Synthetic cathinone structure is related to amphetamines that are known to be hepatotoxic [50]. Therefore, the studies in liver cells are of great importance to assess the toxic effects of xenobiotics. Our group has recently demonstrated the in vitro hepatotoxic potential of four of the most prevalent cathinone derivatives, namely methylone, MDPV, 4-MEC, and pentedrone [32].

In this study, a chiral resolution method for the isolation of enantiomers of MDPV was developed to obtain adequate quantities to test the toxicity of MDPV enantiomers in primary rat hepatocytes and to verify the enantioselectivity. We demonstrated that MDPV enantiomers, as well as the racemic product, induced cell death in a concentrationdependent manner, as shown by the decline in MTT reduction and increase in LDH leakage (Figs. 8, 9, respectively). Both racemic MDPV and each of its enantiomers were significantly hepatotoxic at concentrations as low as $0.2 \mathrm{mM}$ at $48 \mathrm{~h}(p<0.0001$ vs. control $)$, as shown in Fig. 8. The reason why we additionally performed the
LDH leakage assays, under the same experimental conditions, was to circumvent the fact that MDPV, as a ketone, could interfere with redox-based tests like the MTT assays [51]. The obtained results shown in Fig. 9, corroborated the results from the MTT assays, showing cell death in similar magnitude and significance.

It should be emphasized that no marked differences were found between the effects of racemic MDPV and each of its enantiomers (Figs. 8, 9), with the exception of some particular significant differences, namely $0.4 \mathrm{mM} R$-(+)-MDPV in the MTT reduction assay at $48 \mathrm{~h} \quad(p<0.01$ vs. racemic MDPV $), 1.6 \mathrm{mM} S$-(-)MDPV in the LDH release assay at $24 \mathrm{~h}(p<0.001$ vs. racemic MDPV) and $0.8 \mathrm{mM} R-(+)-\mathrm{MDPV}$ at $48 \mathrm{~h}$ in the LDH release assay $(p<0.01$ vs. racemic MDPV). With these results we can conclude that there is no MDPV enantioselectivity for its toxicity in this cellular in vitro model.

\section{Conclusions}

LC method using polysaccharide-based CSPs under normal phase elution conditions was effective for the enantiomeric separation of synthetic cathinones. All the synthetic cathinones were efficiently enantioseparated with $\alpha$ and Rs 

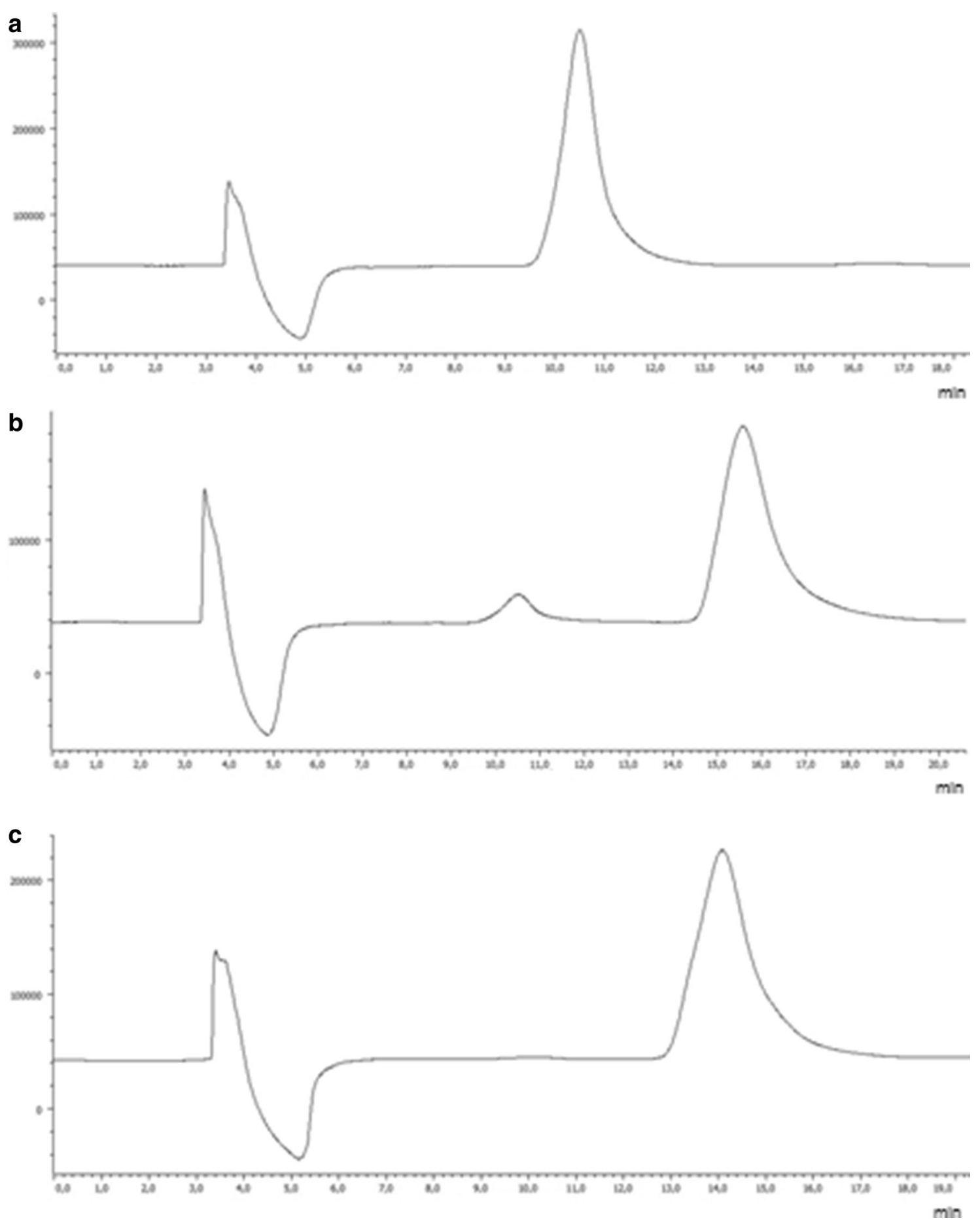

Fig. 7 Liquid chromatograms for the enantiomeric excess of a $S$-(-)-MDPV, b $R$-(+)-MDPV, and $\mathbf{c} R$-(+)-MDPV after reinjection; CSP1 column; mobile phase Hex/EtOH/TEA (97:3:0.1, v/v/v/), flow rate $0.5 \mathrm{~mL}$, UV detection $254 \mathrm{~nm}$

ranging from 1.24 to 3.62 and from 1.24 to 10.52 , respectively. The polysaccharide-based Chiralpak ${ }^{\circledR}$ AS-H CSP was successfully employed for the enantioresolution of this class of compounds; however, the separation of the enantiomers of the synthetic cathinone MDPV was only possible with the polysaccharide-based CSP consisting of 

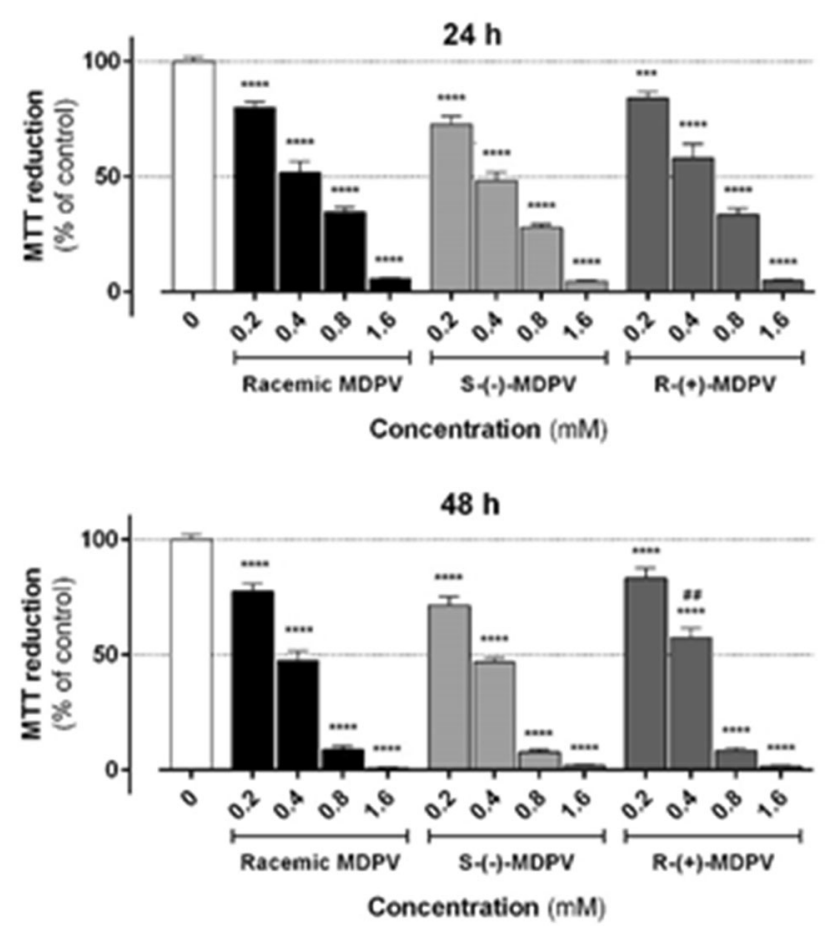

Fig. 8 Reduction of 3-(4,5-dimethylthiazol-2-yl)-2,5-diphenyltetrazolium (MTT) by primary rat hepatocytes exposed to racemic MDPV hydrochloride or individual enantiomers $(0.2-1.6 \mathrm{mM})$ for 24 and $48 \mathrm{~h}$. Data were obtained from three independent experiments, run in quadruplicate. $* * * p<0.001, * * * * p<0.0001$ vs. control. ${ }^{\# \#} p<0.01$ vs. racemic MDPV

amylose tris-3,5-dimethylphenylcarbamate coated onto APS-Nucleosil. All the synthetic cathinones, except 4-MEC, are present in the "legal highs" as racemic mixture (ER approximately 1.0).

The optimized analytical LC conditions were successfully scale-up for the milligram enantioresolution of MDPV. In fact, the enantiomers of MDPV were isolated, for the first time, by semi-preparative LC using amylose tris-3,5-dimethylphenylcarbamate coated onto APS-Nucleosil. The enantiomers were achieved with a high degree of enantiomeric purity (ee $>99 \%$ ) with the levorotatory form as the first enantiomer to be eluted. It was also possible to verify that every form of MDPV was hepatotoxic at a concentrations as low as $0.2 \mathrm{mM}$ at $48 \mathrm{~h}(p<0.0001$ vs. control), without any enantioselectivity, according to the MTT reduction assays performed in primary cultures of rat hepatocytes. The results by LDH leakage assays essentially
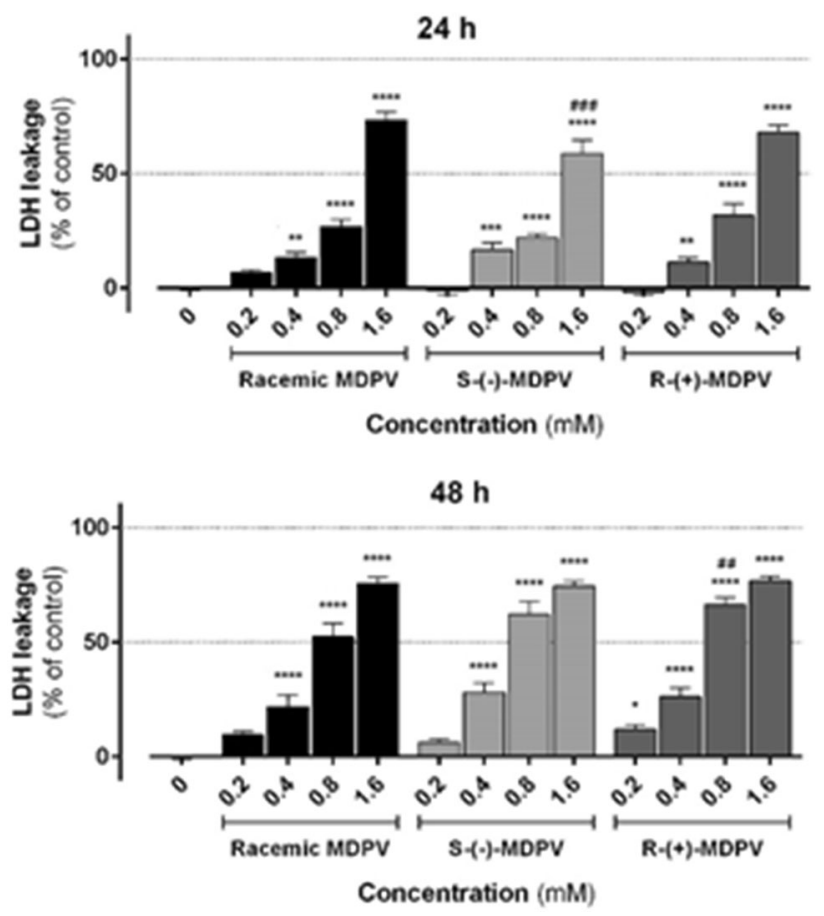

Fig. 9 Lactate dehydrogenase (LDH) release by primary rat hepatocytes exposed to racemic MDPV hydrochloride or individual enantiomers $(0.2-1.6 \mathrm{mM})$ for 24 and $48 \mathrm{~h}$. Data were obtained from three independent experiments, run in quadruplicate. $* p<0.05, * * p<0.01, * * * p<0.001, * * * * p<0.0001$ vs. control. ${ }^{\# \#} p<0.01, " \#$ \#\# $p 0.001$ vs. racemic MDPV

gave the same results. The strategy applied in this study can be applied to other cathinone derivatives to investigate enantioselectivity on their toxicity.

Acknowledgments This work received financial support from the European Union (FEDER funds through COMPETE) and National Funds (FCT, Fundação para a Ciência e Tecnologia) through project Pest-C/EQB/LA0006/2013, and was partially supported by the Strategic Funding UID/Multi/04423/2013 in the framework of the programme PT2020. The authors also thank Sara Cravo for her skillful technical assistance, and CESPU (PHARMADRUGSCESPU-2014).

\section{Compliance with ethical standards}

Conflict of interest There are no financial or other considerations that could lead to a conflict of interest in relation to this study.

Ethical approval All applicable international, national, and/or institutional guidelines for the care and use of animals were followed. 


\section{References}

1. EMCDDA-Europol (2014) Annual report on the implementation of council decision 2005/387/JHA.http://www.emcdda.europa.eu/ attachements.cfm/att_212366_EN_EMCDDA-Europol\% 202012\%20Annual\%20Report_final.pdf. Accessed 3 Dec 2014

2. Johnson LA, Johnson RL, Portier RB (2013) Current "legal highs". J Emerg Med 44:1108-1115

3. Valente MJ, Guedes de Pinho P, de Lourdes Bastos M, Carvalho F, Carvalho M (2014) Khat and synthetic cathinones: a review. Arch Toxicol 88:15-45

4. EMCDDA (2015) New psychoactive substances in Europe. European Monitoring Centre for Drugs and Drug Addiction. http://www.emcdda.europa.eu/attachments.cfm/att_235958_EN_ TD0415135ENN.pdf\#serch='EMCDDA\%2C +2015\%

$2 \mathrm{C}+\mathrm{New}+$ psychoactive + substances $+\mathrm{in}+$ Europe'. Accessed 10 May 2015

5. Namera A, Kawamura M, Nakamoto A, Saito T, Nagao M (2015) Comprehensive review of the detection methods for synthetic cannabinoids and cathinones. Forensic Toxicol 33:175-194

6. Baumann MH, Partilla JS, Lehner KR (2013) Psychoactive "bath salts": not so soothing. Eur J Pharmacol 698:1-5

7. Bijlsma L, Miserez B, Ibáñez M, Vicent C, Guillamón E, Ramsey J, Hernández F (2016) Identification and characterization of a novel cathinone derivative 1-(2,3-dihydro- $1 H$-inden-5-yl)-2-phenyl-2-(pyrrolidin-1-yl)-ethanone seized by customs in Jersey. Forensic Toxicol 34:144-150

8. Uchiyama N, Shimokawa Y, Kikura-Hanajiri R, Demizu Y, Goda Y, Hakamatsuka T (2015) A synthetic cannabinoid FDU-NNEI, two 2-indazole isomers of synthetic cannabinoids AB-CHMINACA and NNEI indazole analog (MN-18), a phenethylamine derivative $N$-OH-EDMA, and a cathinone derivative dimethoxy$\alpha$-PHP, newly identified in illegal products. Forensic Toxicol 33:244-259

9. Katselou M, Papoutsis I, Nikolaou P, Spiliopoulou C, Athanaselis S (2016) $\alpha$-PVP ("flakka"): a new synthetic cathinone invades the drug arena. Forensic Toxicol 34:41-50

10. Fernandes C, Tiritan ME, Pinto M (2013) Small molecules as chromatographic tools for HPLC enantiomeric resolution: pirkletype chiral stationary phases evolution. Chromatographia 76:871-897

11. Glennon RA, Young R, Martin BR, Dal Cason TA (1995) Methcathione ("cat"): an enantiomeric potency comparison. Pharmacol Biochem Behav 50:601-606

12. Jirovsky D, Lemr K, Sevcik J, Smysl B, Stransky Z (1998) Methamphetamine-properties and analytical methods of enantiomer determination. Forensic Sci Int 96:61-70

13. Rasmussen LB, Olsen KH, Johansen SS (2006) Chiral separation and quantification of R/S-amphetamine, R/S-methamphetamine, R/S-MDA, R/S-MDMA, and R/S-MDEA in whole blood by GCEI-MS. J Chromatogr B 842:136-141

14. Gregg RA, Baumann MH, Partilla JS, Bonano JS, Vouga A, Tallarida CS, Velvadapu V, Smith GR, Peet MM, Reitz AB, Negus SS, Rawls SM (2015) Stereochemistry of mephedrone neuropharmacology: enantiomer-specific behavioural and neurochemical effects in rats. Br J Pharmacol 172:883-894

15. Gannon BM, Williamson A, Suzuki M, Rice KC, Fantegrossi WE (2016) Stereoselective effects of abused "bath salt" constituent 3,4-methylenedioxypyrovalerone in mice: drug discrimination, locomotor activity, and thermoregulation. J Pharmacol Exp Ther 356:615-623

16. Lurie IS, Klein RF, Dal Cason TA, LeBelle MJ, Brenneisen R, Weinberger RE (1994) Chiral resolution of cationic drugs of forensic interest by capillary electrophoresis with mixtures of neutral and anionic cyclodextrins. Anal Chem 66:4019-4026
17. Mohr S, Pilaj S, Schmid MG (2012) Chiral separation of cathinone derivatives used as recreational drugs by cyclodextrinmodified capillary electrophoresis. Electrophoresis 33:1624-1630

18. Liau AS, Liu JT, Lin LC, Chiu YC, Shu YR, Tsai CC, Lin CH (2003) Optimization of a simple method for the chiral separation of methamphetamine and related compounds in clandestine tablets and urine samples by $\beta$-cyclodextrine modified capillary electrophoresis: a complementary method to GC-MS. Forensic Sci Int 134:17-24

19. Scarcella D, Tagliaro F, Turrina S, Manetto G, Nakahara Y, Smith FP, Marigo M (1997) Optimization of a simple method for the chiral separation of phenethylamines of forensic interest based on cyclodextrin complexation capillary electrophoresis and its preliminary application to the analysis of human urine and hair. Forensic Sci Int 89:33-46

20. Merola G, Fu H, Tagliaro F, Macchia T, McCord BR (2014) Chiral separation of 12 cathinone analogs by cyclodextrin-assisted capillary electrophoresis with UV and mass spectrometry detection. Electrophoresis 35:3231-3241

21. LeBelle MJ, Savard C, Dawson BA, Black DB, Katyal LK, Zrcek F, By AW (1995) Chiral identification and determination of ephedrine, pseudoephedrine, methamphetamine and methcathinone by gas chromatography and nuclear magnetic resonance. Forensic Sci Int 71:215-223

22. Mohr S, Weiss JA, Spreitz J, Schmid MG (2012) Chiral separation of new cathinone- and amphetamine-related designer drugs by gas chromatography-mass spectrometry using trifluoroacetylL-prolyl chloride as chiral derivatization reagent. J Chromatogr A 1269:352-359

23. Taschwer M, Weiss JA, Kunert O, Schmid MG (2014) Analysis and characterization of the novel psychoactive drug 4-chloromethcathinone (clephedrone). Forensic Sci Int 244:e56e59

24. Weiss JA, Mohr S, Schmid MG (2015) Indirect chiral separation of new recreational drugs by gas chromatography-mass spectrometry using trifluoroacetyl-L-prolyl chloride as chiral derivatization reagent. Chirality 27:211-215

25. Weiss JA, Taschwer M, Kunert O, Schmid MG (2015) Analysis of a new drug of abuse: cathinone derivative 1-(3,4-dimethoxyphenyl)-2-(ethylamino)pentan-1-one. J Sep Sci 38:825-828

26. Mohr S, Taschwer M, Schmid MG (2012) Chiral separation of cathinone derivatives used as recreational drugs by HPLC-UV using a CHIRALPAK(R) AS-H column as stationary phase. Chirality 24:486-492

27. Perera RW, Abraham I, Gupta S, Kowalska P, Lightsey D, Marathaki C, Singh NS, Lough WJ (2012) Screening approach, optimisation and scale-up for chiral liquid chromatography of cathinones. J Chromatogr A 1269:189-197

28. Suzuki M, Deschamps JR, Jacobson AE, Rice KC (2015) Chiral resolution and absolute configuration of the enantiomers of the psychoactive "designer drug" 3,4-methylenedioxypyrovalerone. Chirality 27:287-293

29. Taschwer M, Seidl Y, Mohr S, Schmid MG (2014) Chiral separation of cathinone and amphetamine derivatives by HPLC/UV using sulfated ss-cyclodextrin as chiral mobile phase additive. Chirality 26:411-418

30. Wolrab D, Fruhauf P, Moulisova A, Kuchar M, Gerner C, Lindner W, Kohout M (2015) Chiral separation of new designer drugs (cathinones) on chiral ion-exchange type stationary phases. J Pharm Biomed Anal 120:306-315

31. Aturki Z, Schmid MG, Chankvetadze B, Fanali S (2014) Enantiomeric separation of new cathinone derivatives designer drugs by capillary electrochromatography using a chiral stationary phase, based on amylose tris(5-chloro-2-methylphenylcarbamate). Electrophoresis 35:3242-3249 
32. Araújo AM, Valente MJ, Carvalho M, da Silva DD, Gaspar H, Carvalho F, de Lourdes Bastos M, de Pinho PG (2015) Raising awareness of new psychoactive substances: chemical analysis and in vitro toxicity screening of 'legal high' packages containing synthetic cathinones. Arch Toxicol 89:757-771

33. Penders TM, Gestring RE, Vilensky DA (2012) Excited delirium following use of synthetic cathinones (bath salts). Gen Hosp Psychiat 34:647-650

34. Borek HA, Holstege CP (2012) Hyperthermia and multiorgan failure after abuse of "bath salts" containing 3,4-methylenedioxypyrovalerone. Ann Emerg Med 60:103-105

35. Government P (2013) Decreto-Lei n. ${ }^{\circ}$ 54/2013. Diário da República 75

36. Martin SA, Tiritan ME, Crawford AJ, Cass QB, Boyd DR (1994) HPLC with carbohydrate carbamate chiral phases: influence of chiral phase structure on enantioselectivity. Chirality 6:135-140

37. Sousa ME, Tiritan ME, Belaz KR, Pedro M, Nascimento MS, Cass QB, Pinto MM (2006) Multimilligram enantioresolution of low-solubility xanthonolignoids on polysaccharide chiral stationary phases using a solid-phase injection system. J Chromatogr A 1120:75-81

38. Gawley RE (2006) Do the terms "\% ee" and "\% de" make sense as expressions of stereoisomer composition or stereoselectivity? J Org Chem 71:2411-2416

39. Carvalho M, Milhazes N, Remião F, Borges F, Fernandes E, Amado F, Monks TJ, Carvalho F, Lourdes Bastos M (2004) Hepatotoxicity of 3,4-methylenedioxyamphetamine and $\alpha$ methyldopamine in isolated rat hepatocytes: formation of glutathione conjugates. Arch Toxicol 78:16-24

40. Valente MJ, Henrique R, Vilas-Boas V, Silva R, de Lourdes Bastos M, Carvalho F, de Pinho PG, Carvalho M (2012) Cocaineinduced kidney toxicity: an in vitro study using primary cultured human proximal tubular epithelial cells. Arch Toxicol $86: 249-261$

41. Barbosa DJ, Serrat R, Mirra S, Quevedo M, de Barreda EG, Avilla J, Fernandes E, de Lourdes Bastos M, Capela JP, Carvalho F, Soriano E (2014) MDMA impairs mitochondrial neuronal trafficking in a Tau- and Mitofusin2/Drp1-dependent manner. Arch Toxicol 88:1561-1572

42. Fernandes C, Palmeira A, Santos A, Tiritan ME, Afonso C, Pinto MM (2013) Enantioresolution of chiral derivatives of xanthones on (S, S)-Whelk-O1 and L-phenylglycine stationary phases and chiral recognition mechanism by docking approach for $(\mathrm{S}, \mathrm{S})$ Whelk-O1. Chirality 25:89-100

43. Fernandes C, Tiritan ME, Cass Q, Kairys V, Fernandes MX, Pinto M (2012) Enantioseparation and chiral recognition mechanism of new chiral derivatives of xanthones on macrocyclic antibiotic stationary phases. J Chromatogr A 1241:60-68

44. Fernandes C, Brandao P, Santos A, Tiritan ME, Afonso C, Cass QB, Pinto MM (2012) Resolution and determination of enantiomeric purity of new chiral derivatives of xanthones using polysaccharide-based stationary phases. J Chromatogr A 1269:143-153

45. Cavazzini A, Pasti L, Massi A, Marchetti N, Dondi F (2011) Recent applications in chiral high performance liquid chromatography: a review. Anal Chim Acta 706:205-222

46. Lammerhofer M (2010) Chiral recognition by enantioselective liquid chromatography: mechanisms and modern chiral stationary phases. J Chromatogr A 1217:814-856

47. Godoy P, Hewitt NJ, Albrecht U, Andersen ME, Ansari N, Bhattacharya $S$ et al (2013) Recent advances in 2D and 3D in vitro systems using primary hepatocytes, alternative hepatocyte sources and non-parenchymal liver cells and their use in investigating mechanisms of hepatotoxicity, cell signaling and ADME. Arch Toxicol 87:1315-1530

48. Gerets HH, Tilmant K, Gerin B, Chanteux H, Depelchin BO, Dhalluin S, Atienzar FA (2012) Characterization of primary human hepatocytes, HepG2 cells, and HepaRG cells at the mRNA level and CYP activity in response to inducers and their predictivity for the detection of human hepatotoxins. Cell Biol Toxicol 28:69-87

49. Guillouzo A, Corlu A, Aninat C, Glaise D, Morel F, GuguenGuillouzo C (2007) The human hepatoma HepaRG cells: a highly differentiated model for studies of liver metabolism and toxicity of xenobiotics. Chem Biol Interact 168:66-73

50. Carvalho M, Calmo H, Costa VM, Capela JP, Pontes H, Remião F, Carvalho F, de Lourdes Bastos M (2012) Toxicity of amphetamines: an update. Arch Toxicol 86:1167-1231

51. den Hollander B, Sundstrom M, Pelander A, Ojanpera I, Mervaala E, Korpi ER, Kankuri E (2014) Keto amphetamine toxicityfocus on the redox reactivity of the cathinone designer drug mephedrone. Toxicol Sci 141:120-131 